\title{
USANDO MINERAÇÃO DE TEXTOS COMO SUPORTE AO DESENVOLVIMENTO DE RESUMOS NO ENSINO MÉDIO
}

\author{
Margot Zeni Moretto, Colégio Estadual Dosolina Boff, margotgiselem @bol.com.br \\ Clevi Elena Rapkiewicz, CAP/UFRGS, clevi@ufrgs.br
}

\begin{abstract}
Resumo: Este artigo apresenta o resultado de um experimento com o uso de uma ferramenta de mineração de textos como apoio à produção do gênero textual resumo com alunos de Ensino Médio, levando-se em consideração a abordagem realizada na escola a respeito das dificuldades que envolvem a expressão escrita dos alunos principalmente no que diz respeito ao gênero textual resumo. O objetivo foi investigar se o minerador de textos Sobek auxilia como apoio na elaboração de resumos. O estudo mostrou que houve melhora e aprimoramento nos resumos produzidos com o apoio da ferramenta, demonstrando a potencialidade do minerador de textos no auxilio a produção do gênero textual resumo aplicado no contexto escolar.
\end{abstract}

Palavras-chave: produção gênero textual resumo, mineração de textos, Ensino Médio.

\section{USING TEXT MINING AS A TOOL FOR THE DEVELOPMENT OF ABSTRACTS IN DECONDARY EDUCATION}

\begin{abstract}
This article presents the results of an experiment carried out with a text mining tool for the production of text summary with high school students, taking into account the approach the school has adopted on the difficulties in the written expression of the students, especially in regard to the production of text summary. The objective was to determine whether the text mining tool Sobek aids as a support in preparing summaries. The study showed that there was improvement and development in the text summary produced with the support of the tool, which shows the potential of the text mining tool as an aid to the production of standard text summary, applied in the school context.
\end{abstract}

Keywords: production textual gender resumo, text maning, half education.

\section{Introdução}

A leitura e a escrita são essenciais para que o aluno se desenvolva intelectual e socialmente, sendo que o ensino de Língua Portuguesa na escola tem sido um dos principais eixos de discussão devido à necessidade de melhorar a qualidade da educação no país, conforme dados do MEC (PCN, 2001, livro 02, p.19).

Nesse sentido, este estudo apresenta o resultado da utilização de um minerador de textos como apoio no desenvolvimento de resumos no Ensino Médio com o objetivo de contribuir como suporte tecnológico.

O trabalho foi dividido em cinco seções, sendo esta a primeira delas. Na segunda seção, apresenta-se o referencial teórico a respeito da produção textual e a importância da produção de resumos, bem como a mineração de textos e a ferramenta que foi escolhida para ser usada nesta pesquisa. Na terceira seção encontra-se a metodologia empregada

Já na quarta seção, detalham-se os problemas na produção textual dos alunos, bem como os experimentos realizados e suas análises nas quais se apresentam 
evidências nas produções dos resumos sem e com o apoio do minerador de textos Sobek.

E por fim, na quinta e última seção apresentam-se as considerações finais a que se chegou com este estudo.

\section{Referencial Teórico}

Esta seção apresenta uma breve revisão da literatura no que diz respeito à produção textual, tipos e gêneros textuais e a importância da produção de resumos, bem como a mineração de textos e a ferramenta que foi escolhida para ser usada nesta pesquisa.

\subsection{Produção Textual}

A leitura e produção textual são atividades consideradas habituais nas escolas e estão diretamente relacionadas ao desenvolvimento intelectual e social dos alunos. No entanto, são conhecidadas as dificuldades enfrentadas tanto pelos professores na hora da correção, quanto pelos alunos na hora da expressão oral e escrita. Luft (1999, p.43) indica que "... os jovens não sabem falar,... não sabem escrever, a nova geração não tem vocabulário...”.

Nesse sentido, percebe-se que as dificuldades que os alunos possuem na parte escrita são muitas. Para Cabral (2009) os alunos não apresentam dificuldades em se expressar na oralidade através da linguagem coloquial, os problemas surgem quando há necessidade de produção textual, e isso se dá porque na linguagem oral são usados sinais, gestos e expressões, sendo que esses recursos não são explorados na linguagem escrita.

Jolibert (1994) ressalta três operações que são fundamentais na produção de um texto:

\footnotetext{
1- O planejamento textual, que significa não o fato de "fazer um plano", mas de levar em conta, na elaboração do texto, o destinatário e o objetivo;

2- A textualização concerne aos processos postos em ação para linearizar um texto (progressão e conservação de informações durante o texto, conexão, segmentação - problemas de anáforas - substitutos, tempos verbais, conectivos, pontuação em suas funções textuais);

3 - A revisão dos textos (ou releitura) durante a produção ou depois do texto terminado (JOLIBERT, 1994, p. 25).
}

Para isso, é interessante que sejam trabalhadas a escrita e reescrita de textos, fazendo com que o aluno analise o que escreveu, refletindo e comparando seu texto com os dos colegas de turma e também de outras turmas e até fora da escola. Assim, a produção textual poderá estar em constante transformação e será vista como um processo de contínua construção do conhecimento. Ainda de acordo com Jolibert (1994, p. 47), as reescritas correspondem a um aprofundamento do trabalho na produção dos textos, e podem ser parciais, referindo-se a um nível de análise ou a uma parte do texto.

De acordo com os Parâmetros Curriculares Nacionais da Língua Portuguesa (BRASIL, 1997, p.68), a prática da produção textual é um processo complexo que envolve tanto os aspectos cognitivos quanto os aspectos comunicativos do indivíduo e, por isso, deve ser considerada uma atividade discursiva. Para Soares (2003), a escrita é o marco inicial para o desenvolvimento do indivíduo. Assim, é possível perceber que a apropriação da escrita pode vir a ser uma ferramenta para o desenvolvimento do convívio social, a interação verbal, de comunicação e também de lazer. 
De acordo com Teberosky (1995), experiências com gêneros textuais diversos são importantes porque as possibilidades de expressão dependem das oportunidades sociais oferecidas aos indivíduos pelas instituições, sobretudo pela escola. Isso é muito importante que aconteça principalmente quando a escola possui alunos de baixa renda que não tem em casa as mesmas experiências e cobranças com textos que as crianças de classe média. Neste sentido, cabe à escola o desafio de ensinar não apenas os textos com os quais os alunos se deparam em seu cotidiano fora da escola, mas também aos textos que são produtos culturais da própria escola e são usados como instrumentos para desenvolver e avaliar a produção e a compreensão, como é o caso da ficha de leitura, do relatório, da resenha e do resumo.

Para Schneuwly e Dolz (2004, p.88), resumir envolve:

...dizer em poucas palavras, mas do mesmo ponto de vista enunciativo, o que o autor do texto a resumir quis dizer - só pode ser seguida por uma atividade complexa de paráfrase, por meio da qual o 'resumidor' revive, em seu resumo, a 'dramatização discursiva', construída no texto a resumir, a partir de uma compreensão das diferentes vozes enunciativas que nele agem.

Nesse sentido, percebe-se a importância da escola no contexto de ensino e aprendizagem da produção textual dos diversos tipos e gêneros textuais.

\subsubsection{Tipos e Gêneros textuais}

Para um efetivo estudo do gênero textual resumo, temos que relembrar a diferenciação entre tipo textual e gênero textual. Vejamos uma breve definição das duas noções:

(a) Usamos a expressão tipo textual para designar uma espécie de construção teórica definida pela natureza linguística de sua composição \{aspectos lexicais, sintáticos, tempos verbais, relações lógicas\}. Em geral, os tipos textuais abrangem cerca de meia dúzia de categorias conhecidas como: narração, argumentação, exposição, descrição, injunção.

(b) Usamos a expressão gênero textual como uma noção propositalmente vaga para referir os textos materializados que encontramos em nossa vida diária e que apresentam características sócio-comunicativas definidas por conteúdos, propriedades funcionais, estilo e composição característica. Se os tipos textuais são apenas meia dúzia, os gêneros são inúmeros. Alguns exemplos de gêneros textuais seriam: telefonema, sermão, carta comercial, carta pessoal, romance, bilhete, reportagem jornalística, aula expositiva, reunião de condomínio, notícia jornalística, horóscopo, receita culinária, bula de remédio, lista de compras, cardápio de restaurante, instruções de uso, outdoor, inquérito policial, resenha, resumo, edital de concurso, piada, conversação espontânea, conferência, carta eletrônica, bate-papo por computador, aulas virtuais e assim por diante. (MARCUSCHI, 2002, p.23).

Segundo Fiorin e Platão (1997), o resumo é uma redução do texto original, procurando captar suas ideias essenciais, na progressão e no encadeamento em que aparecem no texto. E ainda, resumir é apresentar, com as próprias palavras (paráfrase), os pontos relevantes de um texto, procurando sintetizá-lo. Um bom resumo deve ser claro, objetivo e breve. A mera reprodução de frases do texto, em geral, atesta que ele não foi compreendido. O resumo é um gênero textual muito importante, pois tudo o que lemos, vemos e ouvimos pode ser transformado em um resumo com o intuito de guardar o essencial.

\subsubsection{Importância da produção de resumos}


No estudo publicado por Spinillo (2009), a autora faz duas perguntas muito interessantes, "Qual a importância de ensinar as pessoas a produzir resumos?" e "Teria o resumo alguma finalidade social além das situações acadêmico-escolares?":

Embora produzir resumos seja menos frequente que produzir outros gêneros, é possível listar algumas situações em que é importante sumariar algo, ainda que de forma oral: o resumo do capítulo da novela, do livro lido, do filme ou da peça de teatro, do noticiário da TV, de algum evento ocorrido que merece ser comentado com um amigo etc. Porém, o principal argumento em defesa do resumo é o fato de que o ato de resumir tanto expressa a capacidade de compreensão do indivíduo como também pode ser um recurso auxiliar na compreensão do texto que lhe deu origem. (Spinillo, 2009, p. 364).

Apesar de o resumo ser muito útil tanto na escola quanto fora dela, observa-se que, comparado a outros gêneros textuais, ele tem sido pouco investigado, sendo raras as pesquisas realizadas.

\subsection{Ferramenta de mineração de textos}

A mineração de textos pode ser definida como uma aplicação de sistemas de computação que envolve hardware e software dedicados à análise textual de documentos, com o objetivo de: [1] extrair informação e/ou conhecimento a partir daqueles documentos; [2] descobrir tendências que aqueles documentos possam expor; [3] obter uma melhor visão sobre as pessoas, lugares e coisas fundamentado no que aqueles documentos podem revelar; [4] classificar, organizar e/ou categorizar os documentos ou a informação/conhecimento que eles contêm; e [5] sumarizar um documento em uma forma mais compacta através da condensação (MATTISON, MATTISON, 1999).

Outra definição é a de Feldman e Sanger (2006) para os quais mineração de texto é um método de extração de informações relevantes em bases de dados não estruturados, ou semi-estruturados.

A ferramenta de mineração de textos Sobek foi idealizada como recurso de apoio aos professores no acompanhamento de trabalhos de escrita colaborativa em cursos a distância (MACEDO et al., 2009). No qual os grafos gerados pela ferramenta Sobek dão aos professores uma visão dos trabalhos dos alunos, mostrando conceitos e relações que parecem ser relevantes, além de fornecer pistas sobre problemas, ou sobre a qualidade de um texto. E ainda apoia na avaliação qualitativa do material escrito produzido pelos alunos.

A ferramenta Sobek, também foi empregada na avaliação qualitativa das postagens dos estudantes em fóruns de discussão (AZEVEDO et al., 2010). O uso do minerador proporcionou ao professor a visualização das contribuições relevantes registradas no fórum, observações de como os alunos estavam interagindo na discussão, visualização dos que colocaram poucos textos significativos, além de estimular aqueles que colocaram muitas contribuições relevantes para interagir com os que colocaram poucas.

Na pesquisa realizada por Klemann et al. (2011), a ferramenta Sobek vem atender o problema da dificuldade dos estudantes com relação à produção textual, pois a técnica de mineração de textos permite que sejam extraídos e relacionados os principais conceitos tratados em um texto. Com base nisso, o minerador apresenta um grafo que possibilita a visualização do conteúdo extraído de forma gráfica. Essa facilidade pode ser explorada como forma de apoio à organização de ideias, à compreensão dos principais conceitos de um texto, ao relacionamento destes com conhecimentos já possuídos, e consequentemente à construção textual. 


\section{Metodologia}

Tendo como objetivo de estudo investigar o uso de uma ferramenta de mineração de textos como suporte na elaboração de resumos com alunos de Ensino Médio, a metodologia foi organizada em diversos passos, comentados a seguir:

- levantamento bibliográfico com dois eixos: dificuldades na produção textual e mineração no suporte à produção textual;

- conhecimento dos sujeitos da pesquisa: aplicação de questionário às professoras com o intuito de conhecer a partir do ponto de vista delas a realidade e as dificuldades dos alunos da escola e, também, contato com os alunos para apresentação da proposta de trabalho;

- experimento com a turma sem usar suporte de minerador de textos;

- experimento com a turma usando minerador de textos o qual busca extrair regularidades, padrões ou tendências de um texto.

Depois de realizado o levantamento bibliográfico com os dois eixos: dificuldades na produção textual e mineração no suporte à produção textual foi feito um levantamento a respeito das dificuldades dos alunos na elaboração de resumos e produções textuais aplicando um questionário às professoras que trabalham com $o$ Ensino Médio na escola. No questionário as professoras puderam relatar quais as principais dificuldades encontradas em sala de aula pelos alunos em relação à produção textual de um modo geral e também em relação à elaboração de resumos.

Na sequência foi realizado um trabalho com os alunos, sendo para isso necessária a utilização em algum momento, da sala de aula da turma, a sala de projeção, bem como o Laboratório de Informática da escola. O trabalho foi realizado individualmente e composto por três fases. Na primeira fase foi feito o contato inicial com os alunos e a produção de um resumo de uma crônica sem auxílio de tecnologia para ter-se uma ideia real e concreta de como eles estavam produzindo seus resumos.

A segunda fase foi realizada na sala de projeção na qual foi apresentada a ferramenta de mineração de textos Sobek como possibilidade de apoio na elaboração de resumos, por ser considerado o mais adequado para ser utilizado neste experimento conforme apontamentos de Klemann et al., (2011). Segundo os autores, entre as ferramentas analisadas a que melhor se qualificou para apoiar a produção textual foi a ferramenta Sobek, pois demonstrou ter uma maior capacidade de extrair informações relevantes e relaciona conceitos que são obtidos por uma análise da distância entre os termos de um texto. Além de ser de fácil manuseio, e também a partir dos termos do grafo, os alunos poderem visualizar e esquematizar mentalmente a sequência dos conceitos e suas relações, e assim, formular frases organizando a sua produção textual.

Segue modo de operação do minerador Sobek:

(1) Copia-se o texto que se quer trabalhar para a área de entrada de dados da ferramenta. Alternativamente, carrega-se um texto em formato $t x t$, doc ou $p d f$.

(2)A partir deste texto, cria-se uma base de conceitos automaticamente através do processo de mineração de textos (utilizando o botão "Extrair Conceitos"). Estes conceitos correspondem a um conjunto de palavras e termos que ocorrem com mais frequência no texto, excluindo-se artigos, preposições, e outras palavras consideradas sem significado relevante. Os parâmetros "número médio de conceitos ${ }^{1}$, stop-words ${ }^{2}$ e selecionar a frequência mínima ${ }^{3 "}$ " estão presentes nas Configurações.

\footnotetext{
${ }^{1}$ Podemos selecionar o número médio de conceitos que aparecem no grafo entre 15,30 e 50 conceitos.
} 
(3) Extraídos os conceitos, gera-se um grafo com os conceitos mais frequentes e seus relacionamentos.

Após os alunos terem conhecimento dessa ferramenta foi realizada a terceira fase na qual foi utilizado o Laboratório de Informática. Nesse momento foi solicitada aos alunos a elaboração de um resumo usando essa tecnologia com um conto que foi dado previamente.

Por último foram verificados os resumos dos alunos com e sem tecnologia para constatar se houve mudanças significativas entre eles.

\section{Análise do estudo}

Esta seção apresenta os problemas na produção textual dos alunos da escola, a análise do experimento de produção de resumos com e sem o apoio tecnológico, bem como a análise geral do trabalho realizado.

\subsection{Problemas na produção textual dos alunos na perspectiva das docentes}

No questionário de diagnóstico respondido pelas professoras, podemos ter uma ideia de quais são as principais dificuldades de produção textual e resumo desses alunos.

Em relação à produção textual de um modo geral pode-se dizer que os alunos possuem dificuldades que vão desde a diferenciação dos tipos de textos e gêneros textuais, falta de vocabulário elaborado, ortografia, pontuação, acentuação, concordância verbal e nominal, até a falta de leitura para ter um maior conhecimento dos assuntos atuais.

Já na elaboração de resumos, segundo as professoras, os alunos têm dificuldades de sintetizar as ideias, não conseguem distinguir dados fundamentais, não conseguem eliminar dados desnecessários, realizam cópias de frases do texto original, não se preocupam com a coerência textual. Alguns alunos acabam fazendo um resumo maior do que o texto original, outros não conseguem apenas resumir e acabam confundindo o resumo com outros tipos e gêneros textuais. Enfim, apresentam dificuldades em ler e escrever com suas palavras o que está sendo solicitado.

Continuando com os problemas na produção textual dos alunos, de acordo com o ponto de vista e experiência das professoras, essas dificuldades são devidas ao fato dos alunos não prestarem atenção no que está sendo solicitado, não se preocuparem com a leitura para manterem-se bem informados e enriquecerem seu vocabulário, pela falta de criatividade, falta de reler o que escreveram não se importando com as regras ortográficas e gramaticais e também pelo fato dos professores das demais disciplinas, que não seja Língua Portuguesa não cobrarem a parte escrita como deveria ser cobrada.

$\mathrm{Na}$ questão da utilização de tecnologia e mídias como som, imagem, vídeo ou informática no apoio à produção do gênero textual resumo, as professoras afirmaram que o uso de recursos "diferentes" ajuda porque os alunos possuem uma maior facilidade de lidar com elas, além de demonstrarem um maior interesse pela leitura e escrita digitalizada e auxilia também os alunos que possuem uma maior facilidade visual e auditiva.

\footnotetext{
${ }^{2}$ Neste parâmetro podemos optar por Padrão, Adicionar ou Substituir stopwords (artigos, preposições e outras palavras desnecessárias).

${ }^{3} \mathrm{~A}$ seleção da frequência mínima permite que apenas termos com frequência maior que o limite estabelecido sejam considerados na extração de conceitos.
} 


\subsection{Análise do experimento de resumos sem tecnologia}

Conforme descrito anteriormente na metodologia, foi realizado um experimento de elaboração de resumos com os alunos de forma tradicional. No qual foi entregue em sala de aula uma crônica para ser lida individualmente e após coletivamente. Em seguida tiraram-se dúvidas a respeito do significado de certas palavras do texto e na sequência foi solicitado aos alunos que fizessem um resumo.

Foram analisados os resumos dos alunos e constatados vários problemas como: cópia de trechos do texto original, opinião em relação ao texto, falta de coerência textual e de vocabulário elaborado que se usa na linguagem escrita, falta de síntese de ideias, problemas ortográficos e de pontuação. O trecho apontado na Figura 1 mostra um resumo no qual foram copiadas frases do texto original: a técnica da aluna foi literalmente sublinhar frases do texto original e transcrevê-las para seu resumo.

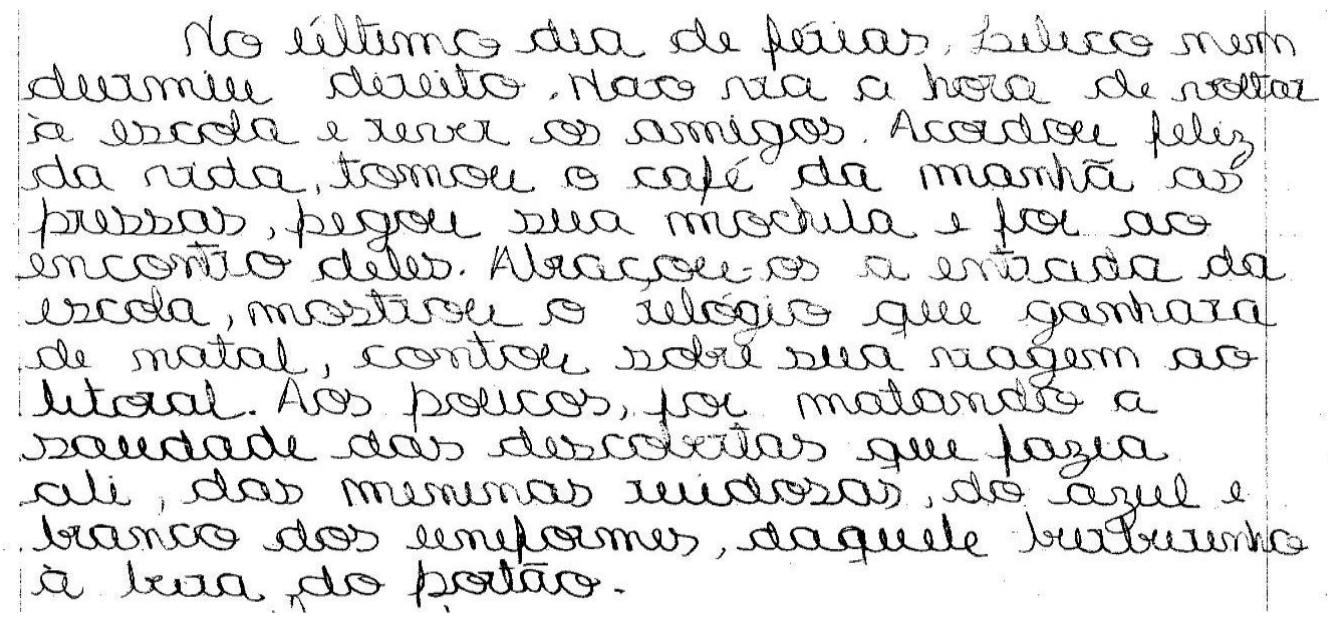

Figura 1: Resumo com cópia de frases do texto original

\subsection{Análise do experimento de resumos com tecnologia}

Neste momento foi apresentado aos alunos o minerador de texto Sobek. Para isso foi mostrado no projetor o modo de operação da ferramenta na qual se copia o texto para a área de entrada de dados do minerador, em seguida clica-se em extrair conceitos e automaticamente será gerado um grafo com os conceitos mais frequentes e seus relacionamentos. Para exemplo de demonstração foi utilizada a crônica a qual os alunos fizeram os resumos sem tecnologia. Na sequência, foi entregue aos alunos um conto para ser lido individual e coletivamente.

Posterior à leitura e esclarecimento de dúvidas a respeito do significado de certas palavras do texto, os alunos se dirigiram ao Laboratório de Informática. Cada aluno utilizou um computador para procurar o conto no site indicado e entrar no site "sobek.ufrgs.br" para carregar a ferramenta de mineração de textos Sobek e colar o texto para ser trabalhado.

Ao final da aula, após todos os alunos terem entregado sua atividade, fizemos um bate-papo para termos uma ideia de como foi a experiência. Todos gostaram de fazer resumo com o apoio de uma ferramenta diferente, segundo eles, o grafo ajudou bastante para a produção do resumo, sendo que apenas um aluno não gostou muito, pois achou que teve de voltar muitas vezes ao texto original para fazer seu resumo. Alguns 
disseram que tiveram dificuldades no início, mas com o auxílio da professora conseguiram saná-las. Enfim, disseram que gostam de fazer atividades diferentes no Laboratório de Informática.

Ao realizar a avaliação dos resumos com o uso da ferramenta Sobek, percebeuse que todos os alunos conseguiram obter melhoras nos seus resumos em comparação àqueles produzidos anteriormente. Até mesmo os alunos que já haviam feito seus resumos corretamente da primeira vez fizeram seus resumos com maior rapidez e acharam que a ferramenta auxilia na compreensão do texto para posterior elaboração do resumo.

O trecho de resumo abaixo (Figura 2), elaborado pela mesma aluna que havia somente copiado frases do texto original (Figura 1), demonstra que com o apoio da ferramenta Sobek conseguiu produzir um bom resumo com as suas palavras e sintetizando as ideias do texto, utilizando para isso o grafo extraído do texto original e fazendo a releitura do mesmo.

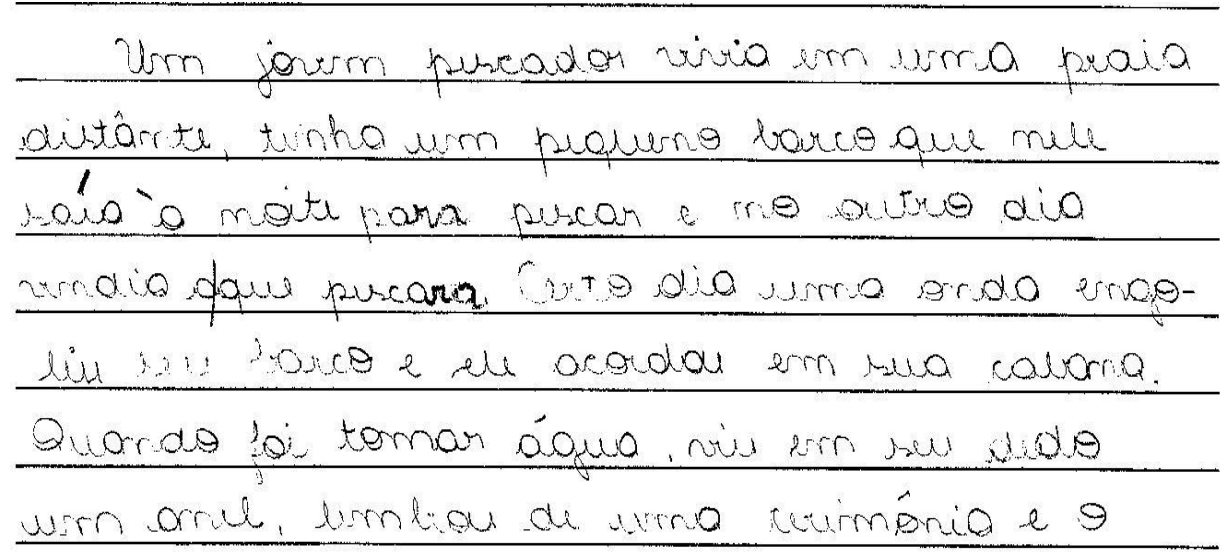

Figura 2: Resumo elaborado corretamente

\subsection{Análise geral}

Ao término de todo o experimento pode-se dizer que houve empenho dos alunos que participaram das aulas com interesse e afinco e conseguiram efetuar as atividades com desenvoltura e atenção, sempre procurando tirar suas dúvidas para assim sanar as eventuais dificuldades encontradas durante o caminho percorrido.

A utilização de diversos recursos além da sala de aula, como a sala de projeção e o Laboratório de Informática, tornaram as aulas mais prazerosas, diversificadas e interativas.

O resultado final foi satisfatório, pois se conseguiu chegar ao objetivo proposto neste trabalho que era constatar a possibilidade de diminuir as dificuldades na elaboração de resumos por parte dos alunos de Ensino Médio usando um minerador de textos como suporte.

\section{Considerações finais}

Sendo a produção textual uma das maiores dificuldades enfrentadas pelos 
estudantes nas escolas e não diferente também a elaboração de resumos, este trabalho teve como objetivo investigar se a mineração de textos auxilia como apoio no desenvolvimento de resumos por alunos de Ensino Médio.

O minerador de textos Sobek foi desenvolvido com um olhar educacional e em comparação a outros mineradores de texto ele se distingue principalmente por apresentar uma maior capacidade de extrair termos relevantes de um texto e por relacionar esses termos entre si. Além de ser de fácil manuseio, ele permitir também a visualização gráfica dos termos e relacionamentos permitindo assim a visualização e esquematização mental da sequência dos termos e suas relações, e assim, no caso dos alunos, formular frases organizando a sua produção textual (KLEMANN et al., 2011).

O papel da escola deve ser de oportunizar o trabalho da escrita e reescrita de textos, fazendo com que os alunos analisem o que escrevem, refletindo e até comparando. Cabe também à escola trabalhar as habilidades de cada aluno em relação aos vários tipos e gêneros textuais para suprir as dificuldades e oportunizar a experiência na produção escrita.

Através deste trabalho constatou-se que a maioria dos alunos da escola possui dificuldades em relação à elaboração de resumos, sendo que este gênero textual pode ser considerado segundo Spinillo (2009), a expressão da capacidade de compreensão do aluno. Essas dificuldades conforme foram verificadas no experimento realizado sem o uso de tecnologia tais como: síntese de ideias, uso das próprias palavras, redução do texto original e sem a reprodução de frases do texto, mostra que os alunos não compreenderam o texto, não o revisitaram para uma segunda leitura e ainda alguns acabaram confundindo resumo com outro gênero ou tipo textual.

Já no experimento realizado com o uso de mineração de textos, no caso deste estudo, com o minerador Sobek, foi possível perceber melhoras e aprimoramento nos resumos dos alunos tais como:

$\checkmark$ Maior organização e síntese das ideias, melhor compreensão e coerência textual, pelo fato dos alunos precisarem revisitar o texto e refletir para fazerem seus resumos;

$\checkmark$ Elaboração de resumos mais breves e completos, sem a reprodução de frases do texto original, devido o conteúdo ser extraído de forma gráfica facilitando a interação na organização das ideias e a compreensão do que aparece no grafo.

Neste sentido, comprovou-se que a ferramenta de mineração de textos Sobek pode servir como suporte no desenvolvimento de resumos com alunos de Ensino Médio.

\section{Referências Bibliográficas}

AZEVEDO, B. F. T. et al. Aplicação da mineração de textos em fóruns de discussão.RENOTE. Revista Novas Tecnologias na Educação, v. 8, p. 77-87, 2010.

BRASIL. Secretaria de Educação Fundamental. Parâmetros Curriculares Nacionais: Língua Portuguesa. Brasília: MEC. São Paulo, 1997.

.Secretaria de Educação Fundamental. Parâmetros Curriculares Nacionais: Língua Portuguesa. Ensino de $1^{\text {a }}$ a $4^{\text {a }}$ séries. Brasília, 1997 p.19. Disponível em: <http://portal.mec.gov.br/seb/arquivos/pdf/portugues.pdf>. Acesso em: outubro 2012.

CABRAL, Marina. Artigo O Texto Escrito. Brasil Escola, 2009. Disponível em: <http://www.brasilescola.com/redacao/texto-escrito.html >.Acesso em: outubro 2012. 
FELDMAN, R., SANGER, J. (2006). Text Mining Handbook. Cambridge, Inglaterra: Cambridge University Press.

FIORIN, José Luiz; PLATÃO, Francisco. Para entender o texto: leitura e redação. 13.ed. São Paulo: Ática, 1997.

JOLIBERT, Josette. Formando crianças leitoras. Porto Alegre: Ares Médicas, 1994.

.Formando crianças produtoras de textos. Tradução por Walkiria M.F. Settineri e Bruno Charles Magne. v.2 Porto Alegre: Artes Médicas, 1994a.

KLEMANN, M. N. Apoio à produção textual por meio do emprego de uma ferramenta de mineração de textos. Porto Alegre: UFRGS, 2011. $91 \mathrm{f}$.Tese (Mestrado em Educação) - Universidade Federal do Rio Grande do Sul, , Porto Alegre, RS, 2011.

KLEMANN, M. et al. (2009). O Emprego da Ferramenta de Mineração de Textos SOBEK como Apoio à Produção Textual. In: SIMPÓSIO BRASILEIRO DE INFORMÁTICA NA EDUCAÇÃO, 20º, Florianópolis. Anais. Disponível em: <http://www.br-ie.org/pub/index.php/sbie/article/view/1154/1057>. Acesso em: junho 2012.

KLEMANN, M. et al. (2011). Análise de Ferramentas de Mineração de Textos para Apoio à Produção Textual. In: SIMPÓSIO BRASILEIRO DE INFORMÁTICA NA EDUCAÇÃO, 22 ${ }^{\circ}$ Aracaju. Anais. Disponível em: <www.brie.org/pub/index.php/sbie/article/download/1866/1632>. Acesso em: setembro 2012.

LUFT, Celso Pedro. Língua e liberdade. 7. ed.São Paulo: Ática, 1999.

MACEDO, A. et al. Using text-mining to support the evaluation of texts produced collaboratively. 9th World Conference on Computers in Education, Bento Gonçalves, 2009.

MARCUSCHI, L. A. Gêneros textuais: definição e funcionalidade.In DIONÍSIO, A. et al. Gêneros textuais e ensino. Rio de Janeiro: Lucerna, 2002.

MATTISON, R.; MATTISON, B. K. Web Warehouse and Knowledge Management.1.ed. McGraw Hill, New York, 1999.

SCHENKER, A. Graph-TheoreticTechniques for Web Content Mining. PhD thesis (Tese Doutorado em Ciências da Computação) - Universityof South Florida, 2003.

SCHNEUWLY, B., \& DOLZ, J. (2004). Os gêneros escolares: Das práticas de linguagem aos objetivos de ensino. In B. Schneuwly\& J. Dolz (Eds.). Gêneros orais e escritos na escola (pp. 71-91). Campinas, SP: Mercado de Letras.

SOARES, Magda. Alfabetização e Letramento. 6. ed. São Paulo: Contexto, 2003.

SPINILLO, Alina Galvão. Eu sei fazer uma história ficar pequena. A escrita de resumo por crianças. InteramericanJournalofPsychology [online] 2009, vol.43,.Disponível em: <http://redalyc.uaemex.mx/src/inicio/ArtPdfRed.jsp?iCve=28412891017>. ISSN 0034-9690. Acesso em: setembro 2012.

TEBEROSKY, A.(1995). Compor textos. In A. Teberosky\& L. Tolchinsky (Eds.), Além da alfabetização (pp. 85-116). São Paulo, SP: Ática. 